\title{
ANALYSIS OF STRESS GENERATED IN THE ENAMEL OF AN UPPER FIRST PREMOLAR: A FINITE ELEMENT STUDY
}

\author{
Andreea Stănuşi'1a $\odot$, Veronica Mercuț ${ }^{1 b} \odot$, Monica Scrieciu'b $\odot$, Sanda Mihaela Popescu ${ }^{2 b} \odot$,

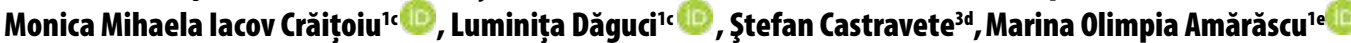

'Department of Proshodontics, Faculty of Dentistry, University of Medicine and Pharmacy of Craiova, Craiova, Romania 2Department of Oral Rehabilitation, Faculty of Dentistry, University of Medicine and Pharmacy of Craiova, Craiova, Romania

${ }^{3}$ Caelynx Europe SRL, Craiova, Romania

aPhDstudent; 'Professor; 'Associate Professor; ' Engineer; ' Lecturer

ABSTRACT DOI: https://doi.org/10.25241/stomaeduj.2020.7(1).art.4

Introduction: This study investigated the distribution and magnitude of stress generated in the enamel of an upper first premolar, after applying normal and excessive occlusal loads in a vertical and horizontal direction, using Finite Element Analysis (FEA).

Methodology: A 3D virtual model of an upper first premolar was analyzed. The CT images of the tooth were converted into 3D data using the program MIMICS and Finite Element Analysis (FEA) was used for the stress study. To better understand the distribution of stress generated by occlusal loading, the situation of the enamel in various 3D virtual models was presented. 14 scenarios for the occlusal loading of the virtual models of the upper first premolar were obtained and the areas with the highest concentration of stress were emphasized.

Results: In the model with the tooth intact, stress values were higher than the admissible ones in the simulation of the excessive vertical loading, normal horizontal loading and excessive horizontal loading. Stress was found in the buccal cusp area and in the cervical area, mainly on the buccal side of the tooth. In the models with horizontal occlusal tooth wear, stress values were higher

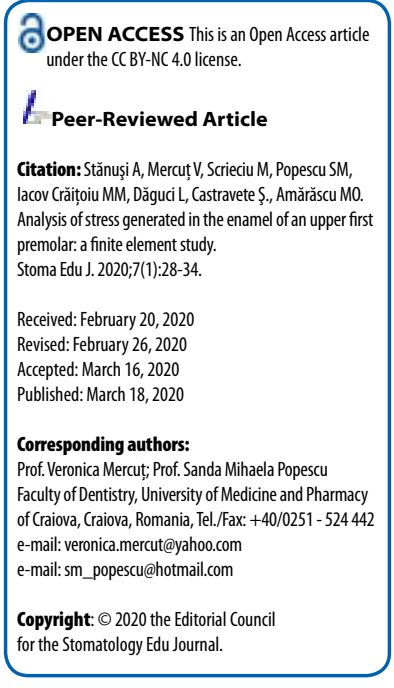
than the admissible ones in the simulation of the excessive vertical loading. Stress was found in the cervical area. In the models with oblique occlusal tooth wear, stress values were higher than the admissible ones in the simulation of the normal and excessive horizontal loading. Stress was found mainly in cervical area, on the buccal side of the tooth.

Conclusions: The most harmful loads were the heavy vertical ones and the horizontal ones, no matter the magnitude.

\section{KEYWORDS}

Tooth Wear; Finite Element Analysis; Stress, Non-Carious Cervical Lesions.

\section{INTRODUCTION}

Non-carious cervical lesions involve the loss of hard dental tissues in the cervical areas of the teeth, without carious activity $[1,2]$. These lesions are important because, in a first stage, they can produce gingival retractions associated with teeth sensitivity [3], and in an advanced stage they can determine endodontic pathology and even the fracture of the teeth involved [4]. Furthermore, non-carious cervical lesions are important because of their high prevalence (5-85\%) [5]. Initially, the toothbrush/ dentifrice abrasion was considered to be the cause for the loss of dental tissues in the cervical area, as stated by Zsigmondy in 1894 [6]. He described these lesions as being wedge-shaped and distributed on the buccal surface of the upper frontal teeth. In 1991, Grippo named the non-carious cervical lesions produced by the mechanism of occlusal loads as "abfraction lesions", so that they could be easily differentiated from the erosion and abrasion lesions [7]. Recently, a series of studies [7-16] claim that many factors are involved in the genesis of non-carious cervical lesions: heavy occlusal loads, biocorrosion, and abrasion. These factors could be encountered individually or in association. It was suggested that heavy occlusal loads from mastication, swallowing and parafunctional movements determine tooth flexure and high stress concentration in the cervical area with the development of enamel cracks. In 2012 Grippo et al. described the mechanism via which heavy occlusal loads generate stress in the cervical area [12]. Depending on the direction of forces, in the tooth structure there appear forces of compression, tension, flexion and shear, all known as stress, which generate fatigue at the enamel-dentine 
ITable 1. Dental materials properties.

\begin{tabular}{|c|c|c|c|c|}
\hline Properties & Enamel & Dentin & Pulp & Periodontal ligament \\
\hline Elastic Modulus of Young (GPa) & $80.35[32-34]$ & $19.89[22,23]$ & $0.002[22]$ & $0.069[22,23]$ \\
\hline Poisson Ratio & $0.33[32-34]$ & $0.31[22,23]$ & $0.45[22]$ & $0.45[22,23]$ \\
\hline
\end{tabular}

ITable 2. Ultimate tensile and compressive strength of dental enamel.

\begin{tabular}{|c|c|}
\hline Ultimate Properties & Enamel \\
\hline Tensile Strength (MPa) & $24[8]$ \\
\hline Compressive Strength (MPa) & $62[13]$ \\
\hline
\end{tabular}

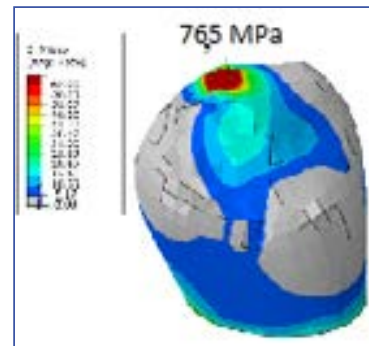

(a)

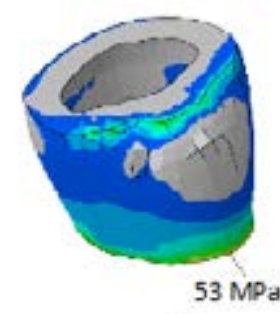

(b)

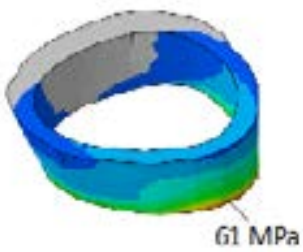

(c)

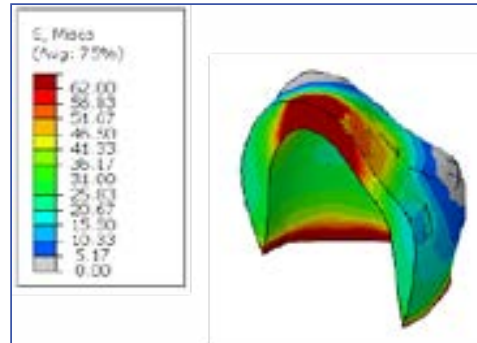

(a)

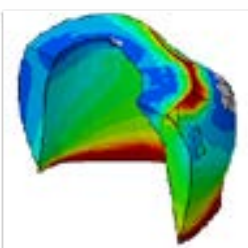

(b)

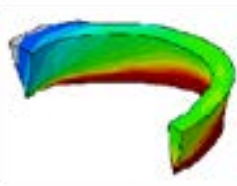

(c)
IFigure 1. Von Mises Stress in enamel: a) intact premolar; b) horizontal tooth wear version $1 ;$ c) horizontal tooth wear version 2.

IFigure 2. Von Mises Stress in enamel: a) intact premolar; b) horizontal tooth wear version 1 ; c) horizontal tooth wear version 2.

junction at the point of force application, and in the case of the non-carious cervical lesions, away from that point [12]. The effects of stress in teeth depend on the magnitude, direction, frequency, point of force application, but also on the axis of the teeth, their form, structure and mobility $[12,17]$. The areas most affected by abfraction lesions are located on the buccal surfaces of teeth, in the cervical zone, with the highest prevalence amongst upper and lower premolars $[8,15,16,18]$. Initially, abfraction lesions appear at the enamel-cement junction in the enamel structure, as a result of reduced thickness of enamel in that area, the absence of enamel rods and low frequency of Hunter Schreger Bands [19]. The aim of this study was to investigate the distribution and magnitude of stress generated by normal and heavy occlusal loads, which were directed vertically and horizontally in the enamel of an upper first premolar, using Finite Element Analysis (FEA) and the virtual model from a previous study [20]. Finite Element Analysis (FEA) is a numerical procedure used in dentistry for the simulation of various clinical situations, in order to study the distribution of stress in the tooth structure and the restorative materials, as a result of occlusal loading [21].

\section{MATERIAL AND METHODS}

The 3D virtual model of the upper first premolar was made using the CT images of a 14 year-old patient [20]. The CT images were converted into 3D data using the MIMICS program (Materialise NV, Leuven, Belgium, 1992) and the 3D virtual model obtained was analysed using Finite Element Analysis (FEA) and the Abaqus/CAE program (ABAQUS Software, S.A.R.L., Versailles, France, 1994). The 3D virtual model consisted of all the tissues of the given premolar: enamel, dentine, pulp and periodontal ligament. The alveolar bone was reconstructed as a parallelepiped, to which the tooth was not rigidly fixed, and between these two structures the periodontal ligament was simulated. The finite element model was a 3D model with tetrahedral elements resulting in 47548 elements and 68504 nodes. The average size of an element was approximately $0.5 \mathrm{~mm}$ per surface. For the elastic modulus of Young and Poisson's ratio of the dental tissues, data from the literature were used as shown in Table 1. The values obtained for the tensions generated in enamel were compared to the ultimate values of tensile and compressive strength 


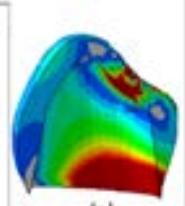

(a)
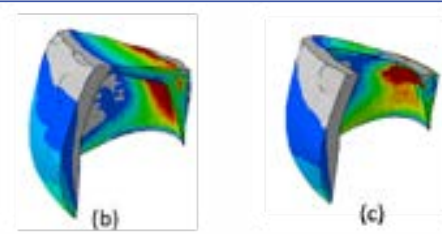

(c)

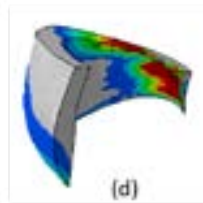

(d)

Figure 3. Tensile stress in enamel: a) intact premolar; b) lateral tooth wear version $1 ; c$ ) lateral tooth wear version 2; d) lateral tooth wear version 3 .

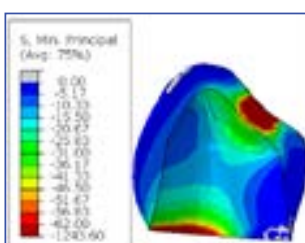

(a)

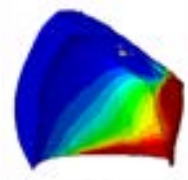

(b)

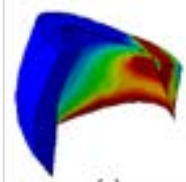

(c)

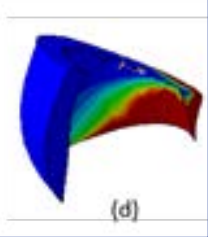

Figure 4. Compressive stress in enamel:a) intact premolar; b) lateral tooth wear version $1 ; c)$ lateral tooth wear version 2 ; d) lateral tooth wear version 3 .

for enamel used in other studies (Table 2) [8,13].

To better understand the distribution of stress generated by occlusal loading, the situation of enamel in various $3 \mathrm{D}$ virtual models was presented. A virtual model of the upper first premolar with no lesion was used to create five more models with different degrees of occlusal tooth wear. The occlusal tooth wear models used in this study represent simulations of some clinical conditions encountered in clinical practice as a consequence of the occlusal load in static mandibular position (occlusal horizontal tooth wear) - 2 models, and the occlusal load in lateral movements of the jaw (oblique occlusal tooth wear) -3 models. Using these models, various scenarios emerged for the occlusal loading applied as a flat surface of a block, in a vertical and horizontal direction. A normal vertical load $(\mathrm{F}=180 \mathrm{~N})$ and an excessive vertical load ( $\mathrm{F}=532 \mathrm{~N}$ ) [24] were applied on the virtual model with the intact premolar and on the two models with horizontal occlusal tooth wear, there resulting six scenarios for the vertical occlusal loading. Also, a normal horizontal load $(F=180 \mathrm{~N})$ and an excessive horizontal load ( $\mathrm{F}=532 \mathrm{~N}$ ) [35] were applied on the virtual model with the intact premolar and on the three models with oblique occlusal tooth wear, there resulting eight scenarios for the horizontal occlusal loading. The study was approved by the Ethics Committee of the Faculty of Dental Medicine of University of Medicine and Pharmacy of Craiova (no. 257/12.10.2019). An informed consent for using the $\mathrm{CT}$ was obtained from the patient.

\section{RESULTS}

In the simulations with horizontal occlusal tooth wear the Von Mises Stress, which is a combination of compressive, tensile and shear stress, the compressive stress was dominant. In the simulations with oblique occlusal tooth wear, the dominant stress was both compressive (Min Principal Stress, the maximum values are negative) and tensile (Max Principal Stress, the maximum values are negative).

\section{a - Simulation of normal vertical load, $F=180 \mathrm{~N}$} In the simulation of a normal vertical loading $(\mathrm{F}=180 \mathrm{~N})$, in the model with the intact premolar, a compressive stress higher than $62 \mathrm{MPa}$, located in the superficial layer of enamel, at the buccal cusp was observed (Fig. 1a). In the models with horizontal occlusal tooth wear, the values of compressive stress were lower. The highest ones were found in the palatal cervical area, but they did not exceed $62 \mathrm{MPa}$ (Fig. 1 b, c).

\section{b - Simulation of excessive vertical load, $F=532 \mathrm{~N}$}

In the simulation of an excessive vertical loading $(\mathrm{F}=532 \mathrm{~N})$, in all models, the compressive stress was higher than $62 \mathrm{MPa}$ (Fig. 2 a, b, c), the maximum value being found in the model with the intact premolar (Fig. 2a). Regarding the distribution of the compressive stress in enamel, in the model with the intact premolar, it was located at the buccal cusp affecting the whole enamel layer and in the cervical area (Fig. 2a). In the models with horizontal occlusal tooth wear, the maximum values for the compressive stress were located in the cervical area of the enamel (Fig. 2 b, c).

\section{c- Simulation of normal horizontal load, $F=180 \mathrm{~N}$}

In the simulation of normal horizontal loading $(F=180 N)$, in the model with the intact premolar, the tensile stress (Max Principal Stress) exceeded $24 \mathrm{MPa}$ in the occlusal area and in the cervical lingual distal area (Fig. 3a). In the models with oblique occlusal tooth wear, the highest values for the tensile stress were found at the palatal cusp (Fig. 3 b, c, d).

The values for the compressive stress generated exceeded $62 \mathrm{MPa}$ in the buccal cervical area and in the occlusal area in the model with the intact premolar (Fig. 4a). In the models with oblique occlusal tooth wear, these small values for the compressive stress were found at the palatal cusp and in the cervical palate-distal area (Fig. 4 b, c, d).

\section{d - Simulation of excessive horizontal load, $F=532 \mathrm{~N}$}

In the simulation of an excessive horizontal loading $(\mathrm{F}=532 \mathrm{~N})$ in the model with the intact premolar, the tensile stress (Max Principal Stress) exceeded $24 \mathrm{MPa}$ in the occlusal area and in the cervical disto- linguo-mesial area (Fig. 5a). In the models with oblique occlusal tooth wear, these high values for the tensile stress were found in the occlusal and 

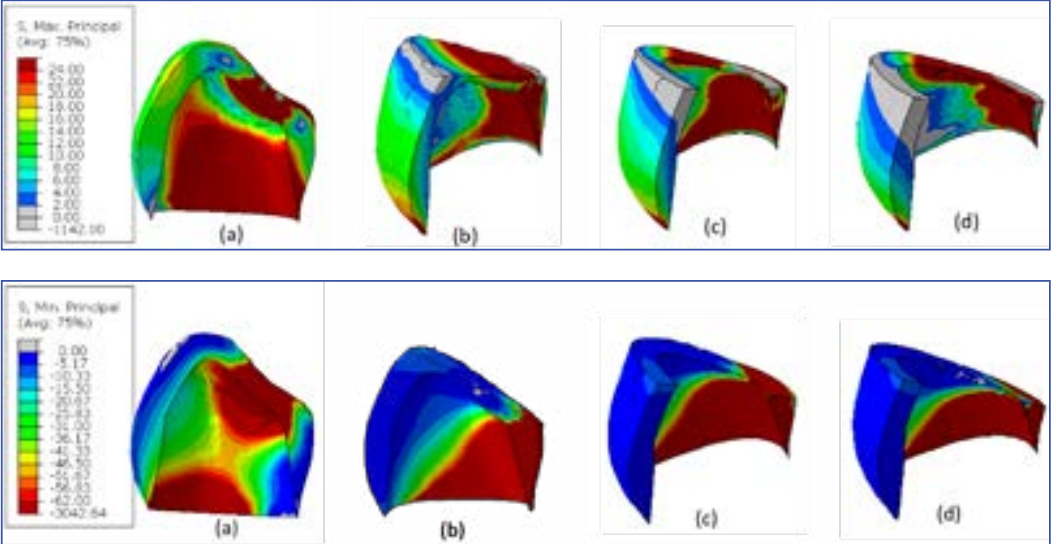

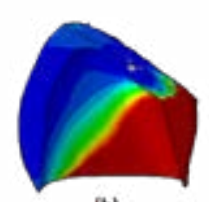

(b)

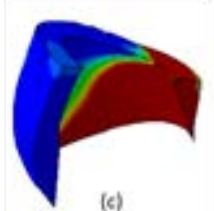

(c)

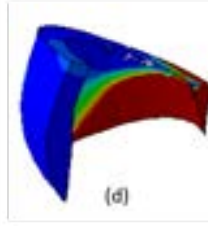

Figure 5. Tensile stress in enamel: a) intact premolar; b) lateral tooth wear version $1 ; c$ ) lateral tooth wear version 2; d) lateral tooth wear version 3.

Figure 6. Compressive stress in enamel: a) intact premolar; b) lateral tooth wear version $1 ;$ c) lateral tooth wear version 2; d) lateral tooth wear version 3 . palatal area and less in the cervical area (Fig. 5 b, c, d). The values for the compressive stress (Min Principal Stress) generated exceeded $62 \mathrm{MPa}$ in the occlusal area and in the cervical buccal area in the model with the intact premolar (Fig. 6a). In the models with oblique occlusal tooth wear, these small values for the compressive stress were found in the occlusal and palatal area, towards the distal part of the tooth (Fig. 6 b, c, d).

14 scenarios for the occlusal loading of the virtual models of the upper first premolar were obtained and the areas with the highest concentration of stress were enhanced. In the model with the tooth intact, the stress values were higher than the admissible ones in the simulation of the excessive vertical loading, normal horizontal loading and excessive horizontal loading. Stress was found in the buccal cusp area and in the cervical area, mainly on the buccal side of the tooth. In the models with horizontal occlusal tooth wear, the stress values were higher than the admissible ones in the simulation of the excessive vertical loading. The stress was found in the cervical area. In the models with oblique occlusal tooth wear, the stress values were higher than the admissible ones in the simulation of the normal and excessive horizontal loading. The stress was found mainly in cervical area, on the buccal side of the tooth. The most harmful forces were the excessive vertical ones and the horizontal ones, no matter the magnitude.

\section{DISCUSSIONS}

This study aimed to analyse the distribution and magnitude of stress generated by normal ( $F=180$ $\mathrm{N})$ and excessive ( $\mathrm{F}=532 \mathrm{~N}$ ) occlusal loads, directed vertically and horizontally. The stress obtained represents the effect of the cumulative action of the compressive and tensile stress in the dental tissues. For this study, a 3D virtual model of an upper first premolar was used. Clinical experience and data from the literature $[8,16,18]$ showed that the upper first premolar had a great susceptibility towards abfraction lesions. Meanwhile, its form and the way the occlusal forces are distributed in its structure make it liable for fractures. For the conversion of the CT images into 3D data the MIMICS program (Materialise NV, Leuven, Belgium, 1992) was used as it was used in prior studies [20, 25-27]. For the stress analysis Finite Element Analysis (FEA) was applied as it was used in prior studies [28-39].

A similar study was performed by Lee et al. in 2002 [8], also using the Finite Element Analysis (FEA) in which a normal vertical force $(F=170 \mathrm{~N})$ was applied at the buccal cusp of an upper second premolar. The highest value of the tensile stress was observed in the cervical area, namely 13.55 MPa [8]. In our study, for the normal vertical force of $180 \mathrm{~N}$, the values for the Von Mises Stress in the cervical area were around 10-15 MPa. The results of our study are similar to those found by Lee et al in-their study in 2002 [8]. In both studies the value of the tensile stress obtained in the cervical area was lower than the admissible one. In 2003, Rees and Jagger [5] performed a study using the Finite Element Analysis (FEA) in order to find an explanation for the high prevalence of noncarious cervical lesions in maxillary teeth. In that study they used three 2D models, representing an upper incisive, upper canine and upper premolar and through the Finite Element Analysis (FEA) recorded the magnitude of stress in the cervical area, obtained after applying a force of $500 \mathrm{~N}$. In the case of the upper premolar, force was applied at the buccal cusp and angulated 45 degrees in a buccal and apical direction. They recorded the tensile stress and compared the values obtained on the buccal surfaces with the ones obtained on the palatal surfaces. The values obtained were similar. Our study had results in accordance with the results obtained in the Rees and Jagger study. However, practice has proven that abfraction lesions were rarely found on the palatal surfaces of the teeth [5] and this phenomenon could be correlated with stress corrosion, meaning that the association between stress and acidic substances cause more lesions than if these factors act alone. Acidic substances are removed by saliva from the palatal surfaces of teeth 6 times more rapidly than the ones located on the buccal surfaces [5]. Furthermore, the enamel affected by demineralization can regain its mechanical resistance as a result of the action of different substances and even saliva [14]. Clinically, these excessive forces or the ones with a horizontal 
direction can be identified in the case of occlusal interferences [39-41], any other clinical situation that modifies occlusion, such as parafunctions, bruxism $[42,43]$ and treatment procedures $[44,45]$. Other studies have tried to find evidence for the causal relationship between occlusion and noncarious cervical lesions $[41,46]$. In these studies, the presence of non-carious cervical lesions was associated with the presence of occlusal wear facets. If excessive occlusal forces can cause noncarious cervical lesions, it would be expected that parafunctional habits such as bruxism and clenching would increase the progression of non-carious cervical lesions. Two studies reported a correlation between bruxism and non-carious cervical lesions [42]. In 2017, Duangthip et al. [47] performed a review to search for correlations between excessive occlusal loads and abfraction lesions and found such an association in $81 \%$ of cases.

\section{CONCLUSIONS}

This study showed the distribution and magnitude of stress obtained in the virtual 3D model of an upper first premolar, after applying normal and excessive, vertical and horizontal forces. The most harmful

\section{REFERENCES}

1. LittleStar ML, Summit JB. Non-carious cervical lesions: an evidence-based approach to their diagnosis. Tex Dent $J$. 2003:120(10):972-980.

[PubMed] Google Scholar Scopus

2. Michael JA, Townsend GC, Greenwood LF, Kaidonis JA Abfraction: separating fact from fiction. Aust Dent J. 2009;54(1):2-8.

[Full text links] [CrossRef] [PubMed] Google Scholar Scopus

3. Lafzi A, Abolfazli N, Eskandari A. Assessment of the etiologic factors of gingival recession in a group of patients in Northwest Iran. J Dent Res Dent Clin Dent Prospects. 2009;3(3):90-93. doi:10.5681/joddd.2009.023.

[Full text links] [PubMed] Google Scholar

4. Pereira FA, Zeola LF, de Almeida Milito G, et al. Restorative material and loading type influence on the biomechanical behavior of wedge shaped cervical lesions. Clin Oral Investig. 2016:20(3):433-441.

[Full text links] [CrossRef] [PubMed] Google Scholar Scopus

5. Rees JS, Jagger DC. Abfraction lesions: myth or reality? J Esthet Restor Dent. 2003;15(5):263-271.

[Full text link] [CrossRef] [PubMed] Google Scholar Scopus 6. Zsigmondy U. [About the wedge-shaped defects on the facia surfaces of the Zajn necks]. [Article in German]. Österr Ungar Vjhrschr Zahnärzte. 1894:1:439-442.

[Full text links]

7. Konagala RK, Mandava J, Anupreeta A, et al. The "Abfraction

- Paradox" - A literature review on biomechanics, diagnosis and management. Int J Sci Res (Ahmedabad). 2018;7(6):46-49. [Full text links]

8. Lee $\mathrm{HE}_{\text {, }}$ in $\mathrm{CL}$, Wang $\mathrm{CH}$, et al. Stresses at the cervical lesion of maxillary premolar--a finite element investigation. J Dent. 2002;30(7-8):283-290.

[Full text links] [CrossRef] [PubMed] Google Scholar Scopus

9. Grippo JO, Simring M, Schreiner S. Attrition, abrasion, corrosion and abfraction revisited: a new perspective on tooth surface lesions [published correction appears in J Am Dent Assoc. 2004 Oct;135(10):1376]. J Am Dent Assoc. 2004;135(8):1109-1165.

[Full text links] [CrossRef] [PubMed] Google Scholar Scopus

10. Addy M, Shellis RP. Interaction between attrition, abrasion and erosion in tooth wear. Monogr Oral Sci. 2006;20:17-31.

[Full text links] [CrossRef] Google Scholar Scopus

11. Borcić J, Antonić R, Urek MM, et al. 3-D stress analysis in first maxillary premolar. Coll Antropol. 2007;31(4):1025-1029.

[Full text links] [PubMed] Google Scholar Scopus forces were the excessive vertical ones and the horizontal ones, no matter the magnitude. Regarding the tooth morphology, the least favourable models for the distribution of stress were the ones with the intact premolar and with lateral tooth wear.

In current practice, these situations are found in the case of occlusal interferences, parafunctions and bruxism.

\section{CONFLICT OF INTEREST}

The authors declare no conflict of interest.

\section{AUTHOR CONTRIBUTIONS}

AS, VM: Concept, protocol, manuscript writing; MS, SMP, MMIC, LD, AMO: Manuscript writing, critical review of manuscript; SC: concept, data entry, data analysis, critical review of manuscript.

\section{ACKNOWLEDGMENTS}

Acknowledge persons who have made substantive contributions to the study. Specify grant or other financial support, citing the name of the supporting organization and grant number.

12. Grippo JO, Simring M, Coleman TA. Abfraction, abrasion biocorrosion, and the enigma of noncarious cervical lesions: a 20year perspective. J Esthet Restor Dent. 2012;24(1):10-23. [Full text links] [CrossRef] [PubMed] Google Scholar Scopus 13. Chun K, Choi H, Lee J. Comparison of mechanical property and role between enamel and dentin in the human teeth. $J$ Dent Biomech. 2014;5:1758736014520809.

[Full text links] [CrossRef] [PubMed] Google Scholar Scopus

14. Shellis RP, Addy M. The interactions between attrition, abrasion and erosion in tooth wear. Monogr Oral Sci. 2014;25:32-45. [CrossRef] [PubMed] Google Scholar Scopus

15. Nascimento MM, Dilbone DA, Pereira PN, et al. Abfraction lesions: etiology, diagnosis, and treatment options. Clin Cosmet Investig Dent. 2016;8:79-87.

[Full text links] [CrossRef] [PubMed] Google Scholar Scopus

16. El-Marakby AM, Al-Sabri FA, Alharbi SA, et al. Noncarious cervical lesions as abfraction: etiology, diagnosis, and treatment modalities of lesions: a review article. Dentistry. 2017;7(6):438. [CrossRef] Google Scholar

17. Kuroe T, Caputo AA, Ohata N, Itoh H. Biomechanical effects of cervical lesions and restoration on periodontally compromised teeth. Quintessence Int. 2001;32(2):111-118.

[PubMed] Google Scholar Scopus

18. Bader ID, Shugars DA. Variation in clinical decision making related to caries. In: Fejerskov O, Kidd EAM, editors. Dental caries: the disease and its clinical management. 2nd ed. Oxford, UK: Blackwell Munksgaard Ltd; 2008

19. Lynch CD, O'Sullivan VR, Dockery P, et al. Hunter-Schreger Band patterns in human tooth enamel. J Anat. 2010;217(2):106-115.

[Full text links] [CrossRef] [PubMed] Google Scholar Scopus 20. Stănuși A, Mercuț V, Scrieciu M, et al. Effects of occlusal loads in the genesis of non-carious cervical lesions - a finite element study. Romanian Journal of Oral Rehabilitation. 2019;11(1):73-81. Google Scholar

21. Zeola LF, Pereira FA, Galvão AdaM, et al. Influence of non carious cervical lesions depth, loading point application and restoration on stress distribution pattern in lower premolars: a 2D finite element analysis. Biosci J. 2015;31(2):648-656. Google Scholar Scopus

22. Gurbuz T, Sengul F, Altun C. Finite element stress analysis of short-post core and over restorations prepared with different restorative materials. Dent Mater J. 2008;27(4):499-507. [Full text links] [CrossRef] [PubMed] Google Scholar Scopus 
23. Munari LS, Cornacchia TP, Moreira AN, et al. Stress distribution in a premolar 3D model with anisotropic and isotropic enamel. Med Biol Eng Comput. 2015;53(8):751-758.

[Full text links] [CrossRef] [PubMed] Google Scholar Scopus

24. Larson TD. The effect of occlusal forces on restorations. J Mich Dent Assoc. 2014;96(9):38-47.

[PubMed] Google Scholar

25. Huang Z, Chen Z. Three-dimensional finite element modeling of a maxillary premolar tooth based on the micro-CT scanning: a detailed description. J Huazhong Univ Sci Technolog Med Sci. 2013;33(5):775-779.

[Full text links] [CrossRef] [PubMed] Google Scholar Scopus 26. Sang $\mathrm{YH}, \mathrm{Hu} \mathrm{HC}$, Lu SH, et al. Accuracy assessment of three-dimensional surface reconstructions of in vivo teeth from cone-beam computed tomography. Chin Med J (Engl). 2016:129(12):1464-1470.

[Full text links] [CrossRef] [PubMed] Google Scholar Scopus 27. Vătu $M$, Crăitoiu $M M$, Vintilă $D$, et al. Determination of resistance forces from mandibular movements through dynamic simulation using kinematic analysis and finite elements method. Romanian Journal of Oral Rehabilitation. 2018;10(1):20-28.

Google Scholar

28. Palamara JE, Palamara D, Messer HH. Strains in the marginal ridge during occlusal loading. Aust Dent J. 2002;47(3):218-222.

[Full text links] [CrossRef] [PubMed] Google Scholar Scopus 29. Nishigawa G, Matsunaga T, Maruo Y, et al. Finite element analysis of the effect of the bucco-lingual position of artificial posterior teeth under occlusal force on the denture supporting bone of the edentulous patient. J Oral Rehabil. 2003;30(6):646652.

[Full text links] [CrossRef] [PubMed] Google Scholar Scopus

30. Dejak B, Młotkowski A, Romanowicz M. Finite element analysis of stresses in molars during clenching and mastication. J Prosthet Dent. 2003;90(6):591-597.

[Full text links] [CrossRef] [PubMed] Google Scholar

31. De Jager N, Pallav P, Feilzer AJ. The influence of design parameters on the FEA-determined stress distribution in CADCAM produced all-ceramic dental crowns. Dent Mater.

2005;21(3):242-251.

[Full text links] [CrossRef] [PubMed] Google Scholar Scopus

32. De Jager $N$, de Kler $M$, van der Zel JM. The influence of different core material on the FEA-determined stress distribution in dental crowns. Dent Mater. 2006;22(3):234-242.

[Full text links] [CrossRef] [PubMed] Google Scholar Scopus

33. Ates M, Cilingir A, Sülün T, et al. The effect of occlusal contact localization on the stress distribution in complete maxillary denture. J Oral Rehabil. 2006;33(7):509-513.

[Full text links] [CrossRef] Google Scholar Scopus

34. Hattori $Y$, Satoh $C$, Kunieda $T$, et al. Bite forces and their resultants during forceful intercuspal clenching in humans. $J$ Biomech. 2009;42(10):1533-1538.

[Full text links] [CrossRef] [PubMed] Google Scholar Scopus
35. Coelho PG, Silva NR, Thompson VP, et al. Effect of proximal wall height on all-ceramic crown core stress distribution: a finite element analysis study. Int J Prosthodont. 2009;22(1):78-86.

[PubMed] Google Scholar Scopus

36. Fu G, Deng F, Wang $L$, Ren A. The three-dimension finite element analysis of stress in posterior tooth residual root restored with postcore crown. Dent Traumatol. 2010;26(1):64-69.

[Full text links] [CrossRef] [PubMed] Google Scholar Scopus

37. Jiang W, Bo H, Yongchun G, LongXing N. Stress distribution in molars restored with inlays or onlays with or without endodontic treatment: a three-dimensional finite element analysis. J Prosthet Dent. 2010;103(1):6-12.

[CrossRef] Google Scholar Scopus

38. Hasegawa A, Shinya A, Nakasone Y, et al. Development of 3D CAD/FEM analysis system for natural teeth and jaw bone constructed from X-Ray CT images. Int J Biomater. 2010;2010:659802.

[Full text links] [CrossRef] Google Scholar

39. Brandini DA, Trevisan CL, Panzarini SR, Pedrini D. Clinical evaluation of the association between noncarious cervical lesions and occlusal forces. J Prosthet Dent. 2012;108(5):298-303.

[Full text links] [CrossRef] [PubMed] Google Scholar Scopus

40. Brandini DA, Pedrini D, Panzarini SR, et al. Clinical evaluation of the association of noncarious cervical lesions, parafunctional habits, and TMD diagnosis. Quintessence Int. 2012;43(3):255-262. [Full text links] [PubMed] Google Scholar Scopus

41. Wood ID, Kassir AS, Brunton PA. Effect of lateral excursive movements on the progression of abfraction lesions. Oper Dent 2009;34(3):273-279.

[FullTextLink] [CrossRef] [PubMed] Google Scholar Scopus

42. Ommerborn MA, Schneider C, Giraki M, et al. In vivo evaluation of noncarious cervical lesions in sleep bruxism subjects. J Prosthet Dent. 2007:98(2):150-158.

[Full text links] [CrossRef] [PubMed] Google Scholar Scopus

43. Antonelli JR, Hottel TL, Garcia-Godoy F. Abfraction lesionswhere do they come from? A review of the literature. J Tenn Dent Assoc. 2013;93(1):14-21.

[PubMed] Google Scholar

44. Bernhardt O, Gesch D, Schwahn C, et al. Epidemiologica evaluation of the multifactorial aetiology of abfractions. J Oral Rehabil. 2006;33(1):17-25.

[Full text links] [CrossRef] [PubMed] Google Scholar Scopus

45. Vasudeva $G$, Bogra $P$. The effect of occlusal restoration and loading on the development of abfraction lesions: A finite element study. J Conserv Dent. 2008;11(3):117-120.

[Full text links] [CrossRef] [PubMed] Google Schola

46. Telles D, Pegoraro LF, Pereira JC. Incidence of noncarious cervical lesions and their relation to the presence of wear facets. $J$ Esthet Restor Dent. 2006;18(4):178-184.

[Full text links] [CrossRef] [PubMed] Google Scholar Scopus

47. Duangthip $\mathrm{D}$, Man $\mathrm{A}$, Poon $\mathrm{PH}$, et al. Occlusal stress is involved in the formation of non-carious cervical lesions. A systematic review of abfraction. Am JDent 2017·30(4):212-220.

[Full text links] [PubMed] Google Scholar Scopus

\section{Andreea STĂNUŞI}

DMD, PhD Student, Prosthodontic Medical Resident Department of Proshodontics

Faculty of Dentistry

University of Medicine and Pharmacy of Craiova

Craiova, Romania

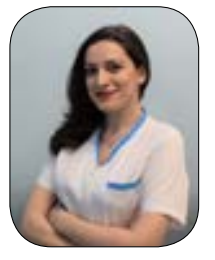

Andreea Stănuşi (DOB: September 22, 1992) graduated from the Faculty of Dentistry, University of Medicine and Pharmacy of Craiova in 2017 and became Medical Resident in Prosthodontics. As a student, she held various positions: President of the Craiova Stomatology Students Society (2013-2014), Member of the Faculty Council (2016-2017), Member of the University Senate (2016-2017). As a postgraduate her activity is still connected with the academic life. In 2017 she became a PhD student under the guidance of University Professor Veronica Mercut, her research interest being the etiology and treatment of tooth wear. In 2019 she published the results of an experiment in which the stress involved in the etiology of tooth wear was examined ("Effects of occlusal loads in the genesis of non-carious cervical lesions - a Finite Element Study"). 


\section{Ouestions}

\section{Non-carious cervical lesions can produce in a first stage:}

$\square$ a. endodontic pathology;

ab. gingival retractions associated with teeth sensitivity;

uc. fracture of the teeth involved;

$\square$ d. periodontal pockets.

\section{The areas most affected by abfraction lesions are located on:}

a. enhanced thickness of enamel in that area;

ab. reduced thickness of dentine in that area;

Dc. the high frequency of Hunter Schreger Bands;

$\square d$. the low frequency of Hunter Schreger Bands.

\section{Abfraction lesions appear at the enamel-cement junction in the enamel structure, as a result of:}

Da. less than $20 \%$ in the three groups with no statistical difference among groups;

$\square$ b. over $10 \%$ in the three groups with no statistical difference among groups;

ac. over $80 \%$ in the three groups with no statistical difference among groups;

ud. less than $10 \%$ in the three groups with no statistical difference among groups.

\section{The excessive forces or the ones with a horizontal direction involved in the etiology of NCCL, can be identified in the following clinical situations apart from:}

Da.occlusal interferences;

Db. parafunctions;

ac. bruxism;

$\square d$. procedures that do not modify occlusion.
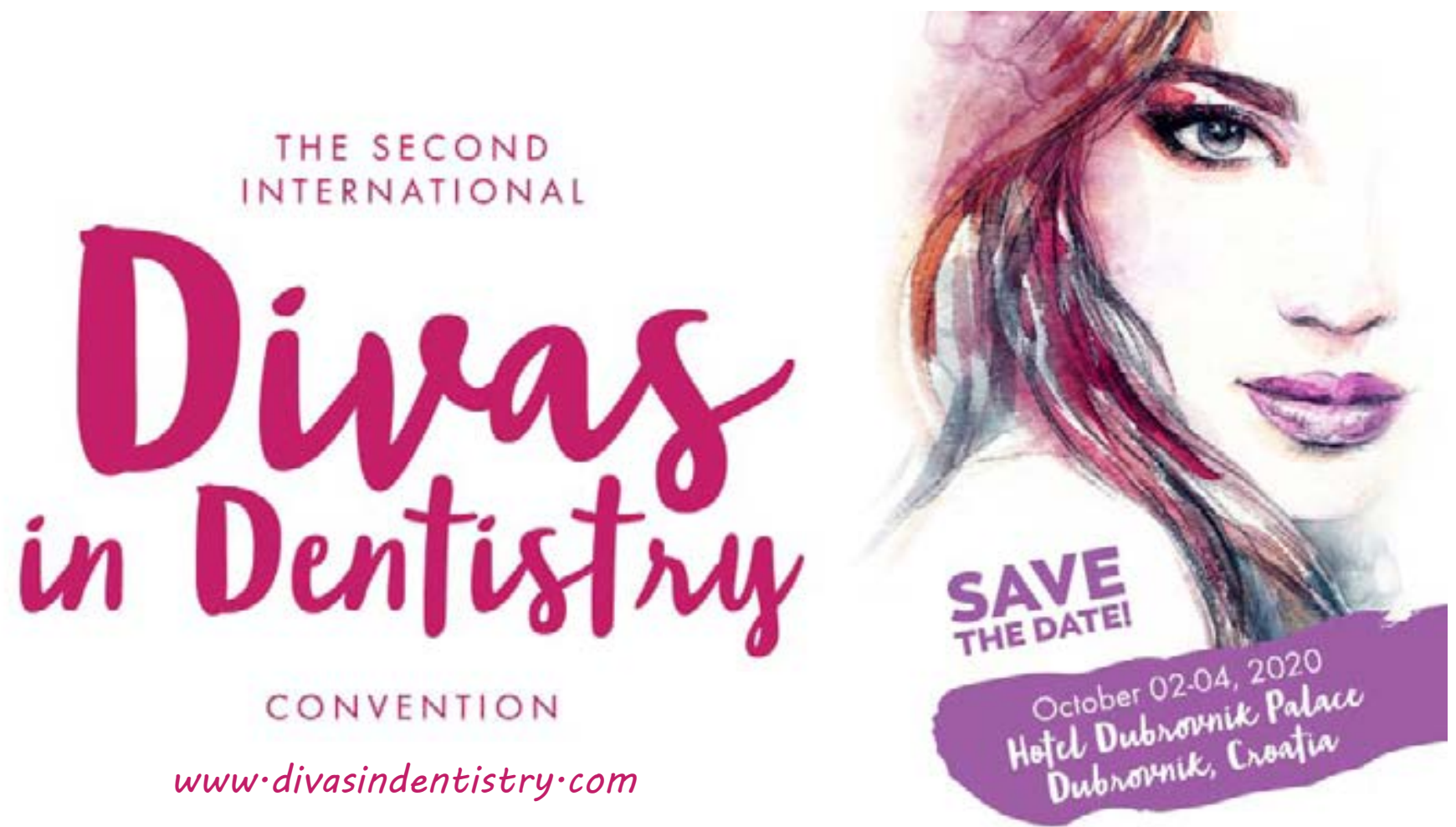